\section{Das Recht auf Leben - Ein Recht der Menschen}

\section{Künzler}

Die UNO-Menschenrechtserklärung sagt aus, dass jeder Mensch ein Recht auf Leben hat und dass er keiner grausamen, unmenschlichen oder entwürdigenden Behandlung oder Strafe unterworfen werden darf. Wir sind uns alle bewusst, dass diese Rechte nach wie vor an zu vielen Orten auf der Welt mit Füssen getreten werden, immer um der staatlichen und politischen Macht willen - sogar in Ländern, die sich rühmen, Verteidiger der Menschenrechte zu sein. Es ist daher gut, von Zeit zu Zeit Bücher zu lesen, die uns Tatsachen und Fakten ins Gedächtnis rufen:

\section{Vereinigte Staaten von Amerika}

Bekanntermassen ist ein wichtiger Faktor für politische Karrieren die positive Stellungnahme zur Todesstrafe. Als eines der fast einzigen an sich demokratischen Länder halten sich die USA in keiner Weise an die Erklärung der Menschenrechte, gehen über internationale Vereinbarungen achselzuckend hinweg, ratifizieren sie nicht, wollen Ausnahmen bewilligt haben, wie z.B. die Hinrichtung von Tätern, die bei der Tat unter 18 Jahren waren. Sie verweigern ausländischen Angeklagten die Aufnahme von Kontakt mit ihren Botschaften u.ä.m.

Ein düsteres Kapitel sind die Todestrakte in all den amerikanischen Staaten, die die Todesstrafe kennen. Der schwärzeste Punkt ist der Todestrakt und die Hinrichtungszelle in Huntsville, Texas. Und darüber liegt seit kurzem ein aufrüttelndes Buch vor, recherchiert und geschrieben von der Mitarbeiterin der «Weltwoche», Margrit Sprecher. Sie schildert detailliert, nach welchen Kriterien in den USA über Leben und Sterben entschieden wird. Man erlebt Menschen hinter Gittern, jahre- und jahrzehntelang eingesperrt, zum Tode verurteilt. Man muss zur Kenntnis nehmen, dass die Männer und Frauen, die in der "death row» auf die Hinrichtung warten, vor allem Schwarze und Latinos sind. Man erlebt fast hautnah den demütigenden Alltag im Todestrakt. Dieses lange Warten ist Folter gleichzusetzen. Diese Folter wird durch die Wärter in zynisch-brutaler Weise oft noch unmenschlicher gestaltet.

Margrit Sprecher: Leben und Sterben im Todestrakt. Haffmans Verlag; 1999. Fr. 36.-

Korrespondenz:

Dr. David Künzler

Jakob Zürrer-Str. 35

CH-8915 Hausen a/A

(Mitglied des Zentralkomitees von ACAT:

Action des Chrétiens pour l'Abolition de la Torture)

\section{Tibet, China}

Dass China über Jahre hinweg die Tibeter unterdrückt und misshandelt hat und dabei versuchte, diejenigen, die an ihrer Religion festhielten, auszurotten, ist an sich bekannt.

Der Leibarzt des Dalai Lama hat nun ein Buch geschrieben, das der- und diejenige, die sich mit Tibet und den Überlebensproblemen des tibetischen Volkes, mit seiner Kultur und Religion beschäftigt, fast gelesen haben muss. In beinahe unbegreiflich liebevoller Art beschreibt der Autor zuerst seine Jugend: Mit 10 Jahren zur Ausbildung ins Kloster zu einer recht harten Schule; dann kam der Wunsch, Arzt zu werden, was ihm mit grossem Durchhaltewillen gegen viele Widerstände schliesslich auch gelang. Er wurde vor der Flucht des Dalai Lama dessen Leibarzt, doch kurz darauf musste der Dalai Lama fliehen. Der Autor blieb zurück und erlebte und überlebte ein rund 20 Jahre dauerndes Martyrium in chinesischen Gefängnissen mit z.T. täglichen Folterungen unbeschreiblicher Art. Dies wird aber in so vergebender Sprache geschildert, dass die Grausamkeiten kaum richtig offensichtlich und dadurch lesbar werden. Man kann viel über Empfinden und Leben von gläubigen Buddhisten lernen. Nach all den Jahren wird er dann doch entlassen und kann nach Dharamsala zu seinem hochverehrten Dalai Lama reisen und wird wieder dessen Leibarzt. Für Ärzte ist das Buch doppelt interessant, da es den echt tibetisch-buddhistischen Zugang und Umgang mit der tibetischen Medizin aufzeigt.

Tensin Choedrak, Der Palast des Regenbogens - Der Leibarzt des Dalai Lama erzählt. Inselverlag. Fr. 37.-.

Das Buch ist primär, aus dem Tibetischen übersetzt, in Frankreich erschienen, daher die folgende französische Besprechung:

\section{Tibet, Chine}

Si l'on se sent concerné par l'oppression chinoise et l'extermination du peuple tibétain, il faut avoir lu ce livre. L'auteur y raconte d'abord sa jeunesse avec beaucoup de tendresse. Entré à l'âge de 10 ans à la dure école du monastère, il souhaita devenir médecin. Après avoir surmonté bien des obstacles à force de persévérance, il devint le médecin personnel du Dalaï Lama. Resté au Tibet après la fuite du Dalaï Lama, il souffrit le martyre durant 20 ans d'emprisonnement et de tortures indescriptibles. Il y survécut pourtant. Le récit est si imprégné de compassion que les cruautés subies ne sont pas relatées de manière crue et en deviennent lisibles. A sa libération, l'auteur a pu rejoindre son vénéré Dalaï Lama et retrouver sa fonction de médecin attitré. Le livre permet d'apprendre beaucoup sur le bouddhisme; il est en outre doublement intéressant pour les médecins, car il décrit très précisément la pratique de la médecine tibétaine.

Tensin Choedrak, Le palais des arc-en-ciel. Paris: Edition Albin Michel; 1998. 